\title{
Dialogismo e polifonia: dos conceitos à análise de um artigo de opinião
}

\author{
Dialogism and Polyphony: from the concepts to the analysis of an Opinion Article
}

\author{
Vera Lúcia Pires \\ Universidade Federal de Santa Maria - Santa Maria - Rio Grande do Sul - Brasil \\ Universidade Católica de Pelotas - Pelotas - Rio Grande do Sul - Brasil \\ Graziela Frainer Knoll \\ Centro Universitário Franciscano - Santa Maria - Rio Grande do Sul - Brasil \\ Centro Universitário Ritter dos Reis - Porto Alegre -Rio Grande do Sul - Brasil \\ Éderson Cabral \\ Instituto Federal de Educação, Ciência e Tecnologia do Rio Grande do Sul - Porto Alegre - Rio Grande do Sul - Brasil
}

$\diamond$

Resumo: Onde não há palavra não há linguagem e, consequentemente, não pode existir relação dialógica. As relações dialógicas pressupõem linguagem, mas não existem no sistema da língua, pois são relações semânticas estabelecidas entre enunciados. A partir da teoria dialógica do Círculo bakhtiniano, o presente artigo discute os conceitos de dialogismo e polifonia na análise dialógica do discurso, a fim de analisar um artigo de opinião. Analisamos as estratégias discursivas utilizadas, as quais confirmam a univocidade do enunciado e, portanto, a ausência de polifonia, ainda que o dialogismo esteja sempre presente.

Palavras-chave: Dialogismo; Polifonia; Análise dialógica do discurso

\begin{abstract}
Where there is no word there is no language and therefore there can be no dialogical relations. Dialogical relations presuppose language, but they do not exist in the language system, because they are semantic relations between utterances. From the dialogic theory of Bakhtin Circle, this article discusses the concepts of dialogism and polyphony in the dialogic discourse analysis in order to examine an Opinion Article. We analyzed the discoursive strategies that were used, which confirm the utterance's univocally and therefore the absence of polyphony, although the Dialogism is always present.
\end{abstract}

Keywords: Dialogism; Polyphony; Dialogic discourse analysis

\section{Introdução}

Inovando todos os estudos sobre a questão da pluralidade semântica das palavras nos discursos, Bakhtin $\left(1987[1963]^{1}\right.$, p. 263) analisou "a vida da palavra, sua passagem de um locutor a outro, de um contexto a outro, de uma coletividade social, de uma geração a outra", examinando-as como uma "unidade migratória" entre discursos, sem jamais se desvincularem de seu trajeto discursivo anterior.

Para o filósofo russo, não há um território interior soberano, estamos sempre na fronteira, olhando para dentro de nós mesmos com os olhos do outro e olhando

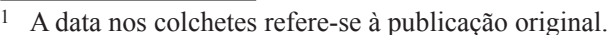

o outro nos olhos. O ser humano não consegue perceber nem a sua própria imagem externa, nenhum espelho ou foto o ajudarão; sua autêntica imagem externa pode ser vista e entendida apenas por outras pessoas, graças à distância especial e ao fato de serem outras. A cultura do outro só se releva com plenitude e profundidade aos olhos de outra cultura. A cultura de uma época, por mais distante que esteja de nós no tempo, não pode estar fechada como algo pronto, plenamente acabado, que se foi e está morto. A compreensão criadora não renuncia ao seu lugar no tempo, nem à sua cultura, não se esquecendo de nada.

Tomo consciência de mim por meio dos outros: deles eu recebo as palavras, as formas e a tonalidade para formação da primeira noção de mim mesmo. A palavra do outro deve transformar-se em minha - alheia (ou alheia - 
minha). "O escritor é aquele que sabe trabalhar a língua estando fora dela, aquele que tem o dom do falar indireto. Exprimir a si mesmo significa fazer de si objeto para o outro e para si mesmo, (a 'realidade da consciência')" (BAKHTIN, 2010 [1979], p. 315). A procura da própria palavra é, de fato, procura da palavra precisamente não minha, mas de uma palavra maior que eu mesmo.

O maior interesse do autor sempre foi a linguagem enquanto uso e em interação social. Especialmente, o momento enunciativo do uso da linguagem, processo que envolve não apenas a presença física de seus participantes como também o tempo histórico e o espaço social de interação. Sua crítica à Linguística, enquanto teoria da abstração - língua -, foi no sentido de faltar a ela uma abordagem da enunciação/enunciado ${ }^{2}$, que desse conta do que, no seu entender, era o discurso, ou seja, "a linguagem em sua totalidade concreta e viva" (BAKHTIN, 1987 [1963], p. 181).

Em contrapartida, Bakhtin e seu grupo propuseramse a investigar o fenômeno complexo da palavra em interação; a enunciação/enunciado como "realidade da linguagem" e, igualmente como "estrutura sócioideológica". A enunciação/enunciado não abrange um sujeito individual, considerado isoladamente, mas é "produto da interação de dois indivíduos socialmente organizados" e do contexto da situação social complexa em que aparece (BAKHTIN, 2001 [1927]; 1986 [1929]).

$O$ processo de interação bakhtiniano funda o princípio dialógico, no qual as palavras apresentam duas faces, ou seja, partem de alguém com destino a outro alguém. Na concepção dialógica de intercâmbio verbal da linguagem, a interação é um ato de parceria comunicacional e valorativa entre parceiros discursivos.

Neste artigo, são discutidos os conceitos de dialogismo e polifonia no escopo da análise dialógica do discurso, com o propósito de analisar o artigo de opinião intitulado A banalização da vida, da autoria de Lya Luft, publicado na revista Veja.

\section{A interação dialógica como fundamento da linguagem}

$\mathrm{O}$ fundamento da linguagem, para o Círculo de Bakhtin é o dialogismo, essa relação com o outro. "A vida é dialógica por natureza. Viver significa participar de um diálogo" (BAKHTIN, 1987[1961], p. 293). Tudo o que me diz respeito vem-me do mundo exterior por meio da palavra do outro. Todo enunciado é apenas um elo de uma cadeia infinita de enunciados, um ponto de encontro de opiniões e visões de mundo. Nessa rede dialógica que é o discurso, instituem-se sentidos que não são originários do momento enunciativo, mas que fazem parte de um continuum. "O falante não é o Adão bíblico, só relacionado com objetos virgens ainda não nomeados, aos quais dá nome pela primeira vez" (BAKHTIN, 2010[1979], p. 300). O processo de compreensão é uma reação às palavras e aos enunciados que nos despertam ressonâncias da vida real, quer dizer: compreender é opor à palavra do locutor uma contrapalavra.

A base do princípio dialógico é a filosofia do diálogo ou da relação ${ }^{3}$ que, afirmando a palavra como dialógica, estabelece a relação "entre" os seres humanos e funda a experiência da intersecção, ou interação. Para essa filosofia, o homem não é um ser individual, mas uma relação dialógica entre um eu e um tu. O tu é condição de existência do eu, uma vez que a realidade do homem é a realidade da diferença entre o eu-tu. $\mathrm{O}$ eu não existe individualmente, senão como abertura para o outro. Origina-se aí a constituição do par fundador - eu-outro - .

O significado de diálogo para o Círculo, entretanto, não se refere, simplesmente, à comunicação ou a troca de opiniões vis-à-vis entre parceiros, senão como um princípio geral de comunhão solidária e coletiva da linguagem, sem qualquer passividade. Diante disso, fazse necessário refletir sobre o ser humano em relação aos (e com os) outros seres em sociedade, pois a "experiência verbal individual do homem toma forma e evolui sob o efeito da interação contínua e permanente com os enunciados individuais do outro" (BAKHTIN, 2010 [1979], p. 313). O fenômeno social da interação é a realidade fundamental da linguagem, realizando-se como uma troca de enunciados, na dimensão de um diálogo (BAKHTIN, 1986[1929], 1981[1930] e 2010[1979]). O sujeito bakhtiniano é constituído na e pela interação dialógica com os outros, reproduzindo e refratando em suas falas e em suas práticas sociais o seu contexto social imediato.

As relações de sentido que ocorrem entre os enunciados de um discurso são determinadas pela situação social imediata e pelo meio social, todavia são organizadas, no que diz respeito ao seu conteúdo e significação, "fora do indivíduo pelas condições extra-orgânicas do meio social" (BAKHTIN, 1986[1929], p. 121). Essas condições reais engendram os sentidos dos enunciados tensionados por distintas posições que habitam o tecido da linguagem, estabelecendo, assim, um relacionamento dialógico de sentidos entre enunciados confrontados. "As relações dialógicas são relações (semânticas) entre toda espécie

\footnotetext{
Preferimos empregar os termos enunciação e enunciado desta maneira, uma vez que na obra de Bakhtin e seus companheiros não são utilizadas as duas palavras, mas apenas uma, a qual dá conta tanto do ato de emissão (enunciação), quanto do produto de tal ato (enunciado). Conferir a esse respeito Bezerra (2010).

3 Um dos principais representantes da filosofia do diálogo foi o filósofo austríaco Martin Buber, citado por Todorov (1981) como influência para o pensamento de Bakhtin sobre dialogismo. A principal obra de Buber, Ich und $d u$, foi publicada em 1923 e foi traduzida, no Brasil, com o título Eu e tu, em 1977
} 
de enunciados na comunicação discursiva" (BAKHTIN, 2010[1979], p. 323), entretanto, também ocorrem dentro de uma só palavra, como igualmente são possíveis entre dialetos sociais, desde que se percebam, nessas relações, visões de mundo conflitantes.

Os sentidos, todavia, não são fixos. Como um processo interativo determinado pela vida social, a linguagem, os discursos e os enunciados estão em permanente evolução. Eles são, de fato, um continuum no fluxo incessante da interação verbal, ligado ao movimento perene da vida e da história. Defendendo essa concepção, o autor afirmava:

O discurso é como o 'cenário' de um certo acontecimento. A compreensão viva do sentido global da palavra deve reproduzir esse acontecimento que é a relação recíproca dos locutores, ela deve 'encená-la', se se pode dizer; aquele que decifra o sentido assume o papel de ouvinte; e para sustentá-lo, deve igualmente compreender a posição dos outros participantes (BAKHTIN, 1981 [1926], p. 199).

Conforme enfatizou Tezza (2003), desde seus primeiros escritos sempre foi primordial, no pensamento do jovem Bakhtin, a palavra viva, juntamente com a atitude valorativa do sujeito que a enuncia e seu tom emocional volitivo, valoração e atitude de vontade da consciência responsiva e responsavelmente ativa. O sentido só é possível porque a natureza da linguagem é essencialmente social: essa é a principal "postura marxista" de Bakhtin, "a postulação da materialidade social do signo" (TEZZA, 2003, p. 186). Existe uma atitude valorativa em relação à palavra viva, que carrega um acento apreciativo anterior e alheio, ou seja, de opiniões e visões de mundo de outros que já a enunciaram anteriormente. Dessa maneira, "a palavra é, no mínimo, dupla” (TEZZA, 2003, p. 199), sendo a relação do locutor com o ouvinte que cria o acontecimento significativo da linguagem. Bakhtin (1986[1929]) afirmava que, por meio da palavra, o ser humano se define em relação ao outro, tanto quanto em relação à coletividade. "A palavra é o território comum do locutor e do interlocutor" (BAKHTIN, 1986 [1929], p. 113). A relação viva entre consciências (centros de valor) é, na vida, uma relação fragmentária, construída palavra por palavra, momento a momento, a qual nos dá provisoriedade em relação à consciência que temos dos outros e de nós mesmos.

Uma mesma língua é coabitada por falares diversos, linguagens sociais dinâmicas que se cruzam, atravessadas pelo social e pela história. São linguagens do plurilinguismo, nas quais se inscrevem pontos de vista e visões ideológicas inseparáveis das transformações da experiência cotidiana (BAKHTIN, 1988 [1975], p. 98). Nesse movimento dinâmico de práticas linguageiras plurais, o autor introduz o conceito de plurilinguismo ou heteroglossia, referente à presença de diversos centros de valor - ou "vozes sociais" -, manifestas na linguagem, pois nenhum sujeito é uma realidade una em nenhum momento de sua existência; todo estilo é um comentário, a atualização de uma tensão valorativa entre consciências assimétricas (TEZZA, 2003, p. 209).

Nesse sentido, Todorov (1981) amplia a contribuição de Bakhtin, afirmando que o filósofo da linguagem esboçou uma nova interpretação da cultura como uma composição de discursos, que retêm a memória coletiva, e em relação aos quais é necessária uma tomada de posição valorativa. É essa interação dialógica e opinante que gera movimento e transformações de sentido.

No momento da enunciação plurilíngue, a palavra, em sua vida concreta, é sempre o ponto de encontro de centros de valores ativos e conflitantes que instauram sentidos. Essa rede concreta de relações dialógicas é, irremediavelmente, social. As relações dialógicas fazem parte de todo fato vivo da linguagem. A vida autêntica da palavra só é possível sob as condições da interação dialógica (BAKHTIN, 2005 [1963], p. 185). O dialogismo é, portanto, essencial à natureza da linguagem.

\section{Do princípio dialógico à alteridade}

O princípio da interação dialógico funda a alteridade como constituinte da consciência do ser humano e de seus discursos. Reconhecendo o dialogismo, encara-se a diferença, uma vez que é a palavra do outro que nos traz o mundo exterior, como já esclarecia Bakhtin,

Nosso discurso, isto é, todos os nossos enunciados [...] é pleno de palavras dos outros. [...] Essas palavras dos outros trazem consigo a sua expressão, o seu tom valorativo, que assimilamos, reelaboramos e reacentuamos, modificamos. [...] Contudo, em qualquer enunciado, quando estudado com mais profundidade, [...] descobrimos toda uma série de palavras do outro semilatentes ou latentes, de diferentes graus de alteridade. (BAKHTIN, 2010[1979], p. 294-299).

Ao produzirmos discursos, não somos a fonte deles, porém intermediários que dialogam e polemizam com os outros discursos existentes em nossa sociedade, em nossa cultura. Como já foi dito, a relação dialógica é polêmica, não há passividade. Nela, os discursos estão em movimento dinâmico, sendo transformados e, até mesmo, subvertidos. O sentido de um discurso jamais é o último: a interpretação é infinita. $\mathrm{O}$ que faz evoluir um diálogo entre enunciados é essa possibilidade sem fim de sentidos esquecidos que voltam à memória, provocando neles a renovação dentro de outros contextos.

Devido a isso, a compreensão é um processo ativo, dialógico e tenso que traz em seu cerne respostas. A 
compreensão de um enunciado vivo é sempre prenhe de respostas (BAKHTIN, 2010[1979]). "A cada palavra da enunciação que estamos em processo de compreender, fazemos corresponder uma série de palavras nossas, formando uma réplica" (BAKHTIN, 1986 [1929], p. 132), a qual, respondendo, evidencia adesão, concordância ou, contrariamente, objeção às ideias expostas. Todos os nossos enunciados são orientados para os outros, pois, asseverava Bakhtin (2010[1979]), o enunciado tem essa particularidade constitutiva de exigir um destinatário que responda.

Essa "responsividade" implica um juízo de valor que, partindo da relação do enunciado com a realidade, com seu autor e com os outros enunciados anteriores, traz para o discurso os elementos ideológicos que o constituem. "Todo enunciado (discurso, conferência, etc.) é concebido em função de um ouvinte, ou seja, de sua compreensão e de sua resposta, bem como de sua percepção avaliativa" (BAKHTIN, 1981 [1930], p. 292).

A orientação social do enunciado em direção ao outro coloca, novamente, em evidência a questão dos valores, cujas categorias fundamentais, segundo Bakhtin (2010 [1979], p. 174, são o eu e o outro, já que "viver significa ocupar uma posição axiológica em cada momento da vida" (BAKHTIN, 2010 [1979], p. 174). Em consequência, nos enunciados se dá o contato entre a língua/gem e a realidade.

Quando reproduzimos o discurso do outro, nele podemos captar uma dupla expressão: a original, do outro, e a expressão atualizada, introduzida por nós no enunciado do qual vai fazer parte. Assim, não só ao locutor cabem os direitos sobre as palavras, mas também ao ouvinte e a todos cujas vozes são ouvidas naquele discurso. A palavra é um drama com três personagens que é representado fora do autor (BAKHTIN, 2010 [1979], p. 328). A interação que une os participantes de uma mesma situação, fazendo-os dividir uma "unidade de condições reais de vida", torna-os solidários, bem como leva-os a apoiar a intersubjetividade verbal em um "nós" discursivo. Quanto mais amplo o horizonte comum dos interlocutores, mais "os enunciados deverão se apoiar em elementos da vida que sejam constantes e estáveis e em avaliações sociais essenciais e fundamentais" (BAKHTIN, 1981 [1930], p. 192).

Contudo, como a avaliação passa pela questão ideológica da representação de visões de mundo, instituise no interior do discurso um jogo dramático de vozes, estabelecendo uma tensão dialética. Os enunciados marcam tal tensão, pois, visto que cada um é único $e$ irreproduzivel na situação em que acontece, todo autor, ao responder e recriar outros enunciados, está produzindo um novo evento, uma singularidade. "O acontecimento na vida do texto, isto é, a sua verdadeira essência, sempre se desenvolve na fronteira de duas consciências, de dois sujeitos" (BAKHTIN, 2010 [1979], p. 311).

Nos discursos do cotidiano é possível observar esse estreito e íntimo encontro com o outro e com a situação vivenciada, em nível de igualdade entre os falantes, o que os torna um campo privilegiado para estudos. $\mathrm{O}$ fato de neles melhor se observar a importância da situação extraverbal para a constituição dos sentidos, facilita a percepção e a apreensão de singularidades discursivas, pois, sendo a palavra "o indicador mais sensível de todas as transformações sociais" (BAKHTIN, 1986 [1929], p. 41) em todas as épocas, é por meio desses discursos cotidianos que se detectam todas as variações e mudanças de sentidos.

A coerência do pensamento multifacetado do Círculo de Bakhtin perpassa todas as obras do grupo e foi expressa nas ligações que embasaram sua proposta teórica e seu método de pesquisa à sua filiação filosófica. $\mathrm{O}$ essencial para o Círculo sempre foi a investigação do ser humano, social e público, em permanente relação intersubjetiva de alteridade, por meio da compreensão de seus discursos.

\section{A polifonia}

Apoiando-nos em Morson e Emerson (2008), podemos afirmar que a palavra diálogo nos textos de Bakthin é empregada em diversos contextos, sendo que uma significação precisa é infactível. Precisar o termo diálogo em Bakhtin é algo utópico. No entanto, os conceitos nos ajudam a realizar exercícios de análise e interpretação. Com o intuito de analisar e interpretar fatos de linguagem, posicionamo-nos diante do diálogo como uma "propriedade constitutiva de todo discurso" (BAKHTIN, 1988 [1975]). Já o conceito de polifonia, para nós, é a própria utopia bakhtiniana.

Percorrer do monologismo, ao dialogismo e à polifonia é uma grande jornada teórica nas obras de Bakhtin e do seu grupo. Mas são conceitos importantes que nos auxiliam a observar os fatos (vivos) de linguagem.

Se o monologismo nos faz perceber que "o outro nunca é outra consciência, é mero objeto da consciência de um 'eu' que tudo enforma e comanda" (BEZERRA, 2007, p. 192); o dialogismo, por sua vez, situa-nos e nos conscientiza que "nenhuma significação se instaura, em nenhum evento concreto, sem a presença de, no mínimo, dois centros de valor" (TEZZA, 2003, p. 232); já a polifonia é a ânsia de um mundo "no qual a multiplicidade de vozes plenivalentes e de consciências independentes e não fundíveis tem direito de cidadania - vozes e consciências que circulam e interagem num diálogo infinito" (FARACO, 2009, p. 77).

Essas noções, postas nessa linearidade, mostramnos que o monologismo tem como meta impor uma 
voz - univocidade - e silenciar outras, enquanto que o dialogismo é a interação entre dois ou mais centros de valor; já a polifonia seria a plenitude e o espaço de todas as vozes.

Embora saibamos que a natureza da linguagem é essencialmente social e que há sempre uma atitude valorativa em relação à palavra viva, que carrega um acento apreciativo anterior e alheio - opiniões e visões de mundo de outros que já a enunciaram anteriormente (TEZZA, 2003, p. 186), raramente encontramos enunciados polifônicos, que aglomeram vozes de diferentes consciências independentes, dando-lhes espaço e abertura.

Como já nos referimos, a palavra é, no mínimo, dupla, conforme Tezza (2003, p. 199), então, a relação de qualquer locutor com o ouvinte/leitor cria um evento significativo da linguagem. Porém, se compreender é encontrar um lugar diante da palavra - o meu lugar -, é possível que se encontre um lugar por um ato responsivo ${ }^{4}$ e não pela abertura ou construção desse espaço pelo autor/enunciador. A responsividade é algo intrínseco a cada ser humano, assim como a dialogia. Todavia, "nem todos" buscam - dentro de seus enunciados - dar lugar a diferentes vozes que circulam e interagem socialmente; assim encontramos no nosso cotidiano enunciados dialógicos, mas raramente polifônicos.

A polifonia será encontrada em obras (como o romance), com uma complexa arquitetura que se abre e representa vozes sociais, dando-lhes espaço e consciência independente, com as quais expressam seus atos emotivosvolitivos. Podemos encontrar, sim, enunciados com nuances polifônicas, mas a polifonia, conforme Bezerra (2007, p. 193)

só pôde realizar-se na era capitalista, e justamente na Rússia, onde uma diversidade de universos e grupos sociais nitidamente individualizados e conflituosos, havia rompido o equilíbrio ideológico, criado as premissas objetivas dos múltiplos planos e as múltiplas vozes da existência, indicando que a essência conflituosa da vida social em formação não cabia nos limites da consciência monológica.

$\mathrm{O}$ que não impede que encontremos nuances polifônicas em outras instâncias, fora das obras de Fiódor Dostoiévski (1821-1881). Contudo, foi Dostoiévski que arquitetou em seus romances um universo de "pessoas livres, capazes de colocar-se lado a lado com seu criador, de discordar dele e até rebelar-se contra ele" (BAKHTIN, 2005). Dostoiévski instituiu vozes (multiplicidade de vozes), consciências independentes e imiscíveis, isto é, cada uma com sua densidade, as quais não se misturam

\footnotetext{
4 Pois "cada palavra já nasce como uma resposta; e a compreensão do que nos dizem é uma contrapalavra" (TEZZA, 2003, p. 200).
}

ou se anulam pela proximidade, ou por compartilhar um mesmo universo enunciativo em algum momento de seus romances; há espaço para todas as vozes de sua esfera social (BAKHTIN, 2005). Assim, a autêntica polifonia de vozes plenivalentes, constituem-se nos romances de Dostoiévski - "em seus romances da maturidade" (FARACO, 2009, p. 77) -, pois, segundo Bakhtin (2005) somente esse autor foi capaz de construir uma multiplicidade de consciências equipolentes, que estão em "pé de absoluta igualdade". Para Bezerra (2007), a polifonia se definirá pela convivência e pela interação de vozes, em um mesmo espaço do romance, todas representando um determinado universo e marcadas por ele.

Dessa forma, encontrar nos gêneros discursivos vozes e consciências independentes, como sendo sujeitos de seus próprios discursos, nos quais os autores não as avaliam desde seu prisma social, de seu arcabouço de valores, mas as tratam como a consciência do outro e não uma projeção da sua própria consciência, é uma tarefa árdua. Por um lado, pode ser encontrado na materialidade linguística dos enunciados concretos a heteroglossia (pluriliguismo/plurivocidade), a luta social entre as diferentes "verdades sociais" (FARACO, 2009, p. 70). Por outro lado, a polifonia é algo exclusivamente observado por Bakhtin na obra de Dostoiévski.

Portanto, consideramos que a polifonia está mais para uma proposta filosófica, um modo de pensar, uma visão de mundo, do que para uma categoria técnica de análise linguística, literária ou textual (TEZZA, 2003). De modo prático, percebemos o conceito de polifonia como um lugar de utopia - um mundo polifônico, onde nenhuma voz requer a verdade e somente a sua verdade, onde nenhuma voz tem a palavra final, pois todas são equipolentes. A polifonia é um instrumento que advém do dialogismo, capaz de "quebrar" discursos monológicos, discursos de mão única, discursos impositivos e com intenção de influenciar, de reger, de doutrinar, de ordenar.

Em um texto, podemos encontrar e mostrar outras vozes e realçar que não há apenas uma direção axiológica. Muitas vozes sustentando a mesma posição axiológica perante o mundo não constitui polifonia, mas um coro, pois caracterizam uma univocidade, ou seja, a falta de pluralidade de pontos de vista e vozes sociais. Em um concerto, cada instrumento opera desde seu lugar, com suas singularidades; todo som é percebido. Cada instrumento com seu respectivo som, entra, cresce, harmoniza-se no tempo-espaço regido pelo maestro. Um texto, para ser polifônico, deve operar com múltiplas vozes e consciências independentes e singulares, que ganham espaço, força e vida, não apenas o lugar concebido pelo sujeito autor. Passamos, a seguir, à averiguação sobre como esses conceitos aparecem ou não aparecem em um exemplar do gênero artigo de opinião. 


\section{Análise do artigo de opinião}

Iniciamos esta seção com as considerações a respeito do gênero discursivo que o texto analisado realiza: o artigo de opinião. $\mathrm{O}$ artigo de opinião intitulado $A$ banalização da vida ${ }^{5}$ foi escrito por Lya Luft para a revista Veja, em edição do ano 2014. Dados divulgados pela publicação demonstram que essa revista apresenta números expressivos com base em circulação e número de assinantes. Também é relevante verificar que seu público é misto no que tange ao gênero social.

O enunciado é, como vimos em Bakhtin (2010), a unidade da comunicação discursiva, determinado "antes de tudo pela situação social mais imediata" (BAKHTIN/ VOLOCHÍNOV, 1986, p. 116). Veremos, a seguir, como suas características podem ser aplicadas ao estudo do artigo de opinião tendo em vista a análise dialógica e a busca pela polifonia, existente ou não.

No âmbito da produção do enunciado, a atividade social engendrada é realizada pela atuação de, pelo menos, três classes de participantes: a autora, que corresponde à escritora brasileira Lya Luft, quem efetivamente assina a coluna ${ }^{6}$ na revista; o veículo de comunicação, que difunde o artigo às incontáveis pessoas que constituem o público; e os leitores do artigo, aqueles a quem se dirige a palavra. Os leitores empíricos são recuperáveis, em certa medida, pelos leitores presumidos da revista, que conta com uma circulação semanal superior a um milhão de exemplares, dentre assinantes e vendas avulsas.

Assim como em qualquer uso da linguagem, a intersubjetividade é construída a partir da alteridade, isto é, da percepção da autora como produtora de um enunciado e da percepção do outro como leitor diante do artigo. Naquele momento, o indivíduo que lê o texto, por uma compreensão responsiva da linguagem, tornase parceiro da interação social realizada. A noção que o sujeito produtor do enunciado tem de seu coparticipante interativo é um dos fatores decisivos para as escolhas discursivas, ou seja, para a decisão de como enunciar.

Como define Bakhtin (2010), a compreensão é a primeira fase da responsividade, em que o papel ativo do outro, ou seja, do leitor, surgirá por meio de atitudes, de pensamentos, da formação de opinião, da produção de enunciados na roda de amigos ou em outras esferas em que atue. A compreensão responsiva é uma atitude ativa porque não se restringe a uma "passagem da linguagem do outro para a minha linguagem" (BAKHTIN, 2010, p. 377).

\footnotetext{
5 Fonte: $<$ http://veja.abril.com.br/blog/ricardo-setti/politica-cia/lya-luft-abanalizacao-da-vida/ $>$. Acesso em: 10 ago.2015

6 A coluna semanal de Lya Luft também está integralmente disponível na página da revista na Internet ( $<$ http://veja.abril.com.br/blog/ricardo-setti/ politica-cia/lya-luft-a-banalizacao-da-vida/>. Acesso em: 10 ago. 2015).
}

A criação é polissêmica, e a compreensão é, ao mesmo tempo, responsiva, ativa e criadora: o sujeito que interpreta o enunciado é capaz de perceber as relações dialógicas estabelecidas com outros enunciados e institui uma atitude avaliadora ou apreciativa em relação ao que é dito. "Não se pode separar compreensão e avaliação: elas são simultâneas e constituem um ato único integral" em que o sujeito compreende a partir de sua visão de mundo particular (BAKHTIN, 2010, p. 378).

Enquanto unidade de sentido, o artigo de opinião publicado em revista está esteticamente limitado pelo espaço da página impressa e pelo tempo de leitura. O artigo, inserido em coluna fixa da publicação, é visualmente programado para ocupar os limites de uma página simples da revista, estando cercado por textos antecedentes e subsequentes que ocupam as outras páginas da publicação. É o acabamento estético do texto que demarca a conclusividade do enunciado e instaura a responsividade. A responsividade poderá materializar-se mediante a adesão ou o repúdio ao discurso. Por ser o canal impresso e gráfico, a comunicação é mediada, e a compreensão ativa decorre da leitura, da compreensão responsiva e das subsequentes respostas ou atitudes em relação ao enunciado, efetivando a alternância de sujeitos prevista em toda situação de comunicação dialógica. Isso significa que, uma vez lido e compreendido, o enunciado suscitará novos enunciados em resposta, realizando o continuum da comunicação.

Como toda unidade de expressão de linguagem, o artigo de opinião materializa uma "relação subjetiva emocionalmente valorativa" (BAKHTIN, 2010, p. 289) do anunciante com o conteúdo veiculado ou com o objeto. Essa relação é verificada na composição e no estilo que caracterizam o gênero discursivo artigo de opinião e, especificamente, a coluna produzida por Lya Luft, com uma visão de mundo que é individual, única e intransferível do sujeito autor.

Quanto às características do gênero, o artigo de opinião destina-se a discutir temas polêmicos ou socialmente relevantes, não só para o autor, mas para os leitores da revista. A comunicação parte de um articulista, endossado pelo veículo, e dirige-se a um amplo número de leitores, cujas opiniões individuais poderão ser favoráveis ou não à tese sustentada. Para que ocorra maior adesão à tese, é empregada a argumentação ao longo do texto.

Conforme a teoria dialógica bakhtiniana, o sujeito efetua avaliações em relação a si mesmo, aos outros e ao mundo. Essa postura ou atitude de atribuir valor às coisas, às pessoas e aos atos de modo geral pode ser vista como uma extensão do sujeito ao utilizar a linguagem. Em suas interações cotidianas, os indivíduos manifestam um envolvimento emotivo-volitivo com o mundo, sendo 
o componente axiológico inerente à nossa existência, uma vez que sempre assumimos determinada postura frente a dilemas.

Esse conceito torna-se bastante visível quando explicitado pela avaliação que, sendo inerente à linguagem em seu uso concreto, pode estar presente nas mais diversas categorias de palavras, porém, torna-se explícita especialmente pelas adjetivações empregadas pela autora. Dentre as adjetivações (adjetivos, locuções adjetivas e orações adjetivas), as quais servem não só para fixar um posicionamento da autora a respeito do tópico temático tratado, mas para enfatizar a sua proposta e enfraquecer, mediante a desqualificação, as vozes potencialmente dissidentes, podemos destacar o trecho:

Bala perdida, traficante, bandido graúdo ou pequeno, e o menor de idade, que é o mais complicado: pelas nossas leis absurdas, sendo menor ele não é de verdade punido. É levado para um estabelecimento hipoteticamente educativo e socializador, de onde deveria sair regenerado, com profissão, com vergonha na cara, sair gente. Não sai. Não, salvo raríssimas exceções, e todo mundo sabe disso. (grifos nossos)

Na passagem, também operam modalizações que servem a esse propósito: "hipoteticamente educativo e socializador", "de onde deveria sair regenerado", subentendendo-se a descrença da autora em relação às medidas socioeducativas existentes e à regeneração do menor que comete crimes.

A articulista coloca a sua posição axiológica individual como a norma predominante dentre todas as posições existentes e possíveis, o que fica explicitado na seguinte passagem, com destaque para a expressão generalizante na posição de sujeito da oração: "Todo mundo sabe que é urgente e essencial reduzir para menos de 18 anos a idade em que se pode prender, julgar, condenar um assassino feroz, reincidente, cruel e confesso". Nesse caso, a expressão "todo mundo" não só representa um "nós" inclusivo, isto é, a segunda pessoa do plural em que a autora incluída, mas a totalidade de sujeitos existentes e possíveis, ainda que isso não tenha uma correspondência real e concreta no mundo, haja vista que diferentes pessoas podem ter opiniões antagônicas sobre um mesmo tema. Sendo assim, "Todo mundo" opera como uma partícula homogeneizadora, que, uma vez inserida na argumentação do texto, tende a calar as vozes potencialmente contrárias à opinião da autora.

Há, ao longo do texto, marcas opositivas, como as conjunções adversativas, que serviriam para inserir a voz do outro, mas estão impregnadas pela posição axiológica da autora e, sendo assim, ao invés de abrirem espaço à contra-argumentação, reforçam a univocidade do enunciado.
As vozes contrárias à opinião predominante no texto, quando não são silenciadas, encontram-se inseridas com o artifício de exclamações e interjeições, que culminam dando um tom pejorativo às outras vozes: "Mas ai vem quem defenda, quem tenha pena, ah! os direitos humanos, ah! são crianças." (grifos nossos).

Dentre as marcas que sinalizam o diálogo entre vozes ou entre interlocutores, está o ponto de interrogação. $A$ priori, em um diálogo, o ponto de interrogação sinaliza uma pergunta e, portanto, abre espaço a uma resposta potencial daquele que lê ou ouve a mensagem questionadora. Entretanto, são empregadas no texto perguntas retóricas, ou seja, perguntas que, não buscam suscitar uma resposta, mas procuram enfatizar o ponto de vista da autora. É o que ocorre nas passagens: "Culpa deles? Certamente não", isentando os policiais de qualquer culpa, em "que civilização estamos nos tornando?" e, por fim, em "Que humanidade estamos nos tornando, nós os abandonados, os expostos, os indefesos, sem proteção nem de uma Justiça confusa, anacrônica, irreal, e, quando a lei é boa, tão mal cumprida?", com a finalidade de reiterar a tese sustentada.

O tom autoritário da articulista em relação à tese que sustenta é repetido nas assertivas ou nas negativas com tom imperativo que, no plano do sentido, ajudam a manter o ponto de vista calamitoso da autora. Isso está presente nas passagens: "aqui se mata e se morre como quem come um pãozinho", "pelas nossas leis absurdas, sendo menor ele não é de verdade punido", "Não sai. Não, salvo raríssimas exceções, e todo mundo sabe disso", "Não se passa semana sem que se noticie criança morta por bala perdida", "Todo mundo sabe que é urgente e essencial reduzir para menos de 18 anos a idade em que se pode prender, julgar, condenar um assassino feroz, reincidente, cruel e confesso", "Pouca esperança real temos".

Conforme sabemos e é preconizado pela teoria dialógica bakhtiniana, o sujeito produtor, ao elaborar seu enunciado, tem em perspectiva o endereçamento e, consequentemente, emprega estratégias discursivas que sirvam ao seu projeto de discurso, antecipando reações do sujeito a quem dirige a palavra. Talvez por essa razão, por prever reações possíveis dos sujeitos leitores, a autora tenta justificar seu tom, empregando termos atenuantes que, contudo, ficam no plano do desejo ou do querer: "Quero escrever uma coluna otimista. Quero escrever poemas delicados, romances intensos, crônicas de amor pela cidade, pelas pessoas, pela natureza, quero tudo isso" (grifos nossos). Em seguida, a autora insere uma conjunção adversativa e emprega uma linguagem metafórica e, principalmente, gráfica para explicar seu posicionamento: "Mas se tenho voz, e vez, não posso falar de flores enquanto o asfalto mostra manchas de 
sangue, famílias são destroçadas, ruas acossadas, casas ameaçadas, seres humanos feito coelhos amedrontados sem ter para onde correr, nem a quem recorrer, e não se vê nem uma luz no fim desse túnel" (grifos nossos).

Como a palavra empregada carrega em si um componente ideológico, condizente com a interpretação de mundo feita pelo produtor do enunciado, temos na palavra um índice sensível também de questões de classe social. Ao afirmar que "matam-se pais de família ou jovens estudantes ou operários", a autora explicita esse tipo de ideologia, em que depreendemos uma valorização da figura patriarcal do "pai de família" e do trabalhador ("operários"), dentre tantas pessoas que constituem a sociedade. Tal avaliação de classe torna-se explícita na declaração: "Não falo em becos onde a violência impera e a mortandade é comum, mas em ruas abertas de bairros de classe média". A autora refere que a violência assola a todos, fato confirmado pelo emprego frequente da expressão "Todo mundo", entretanto, os assassinatos em becos têm sua relevância diminuída pelas escolhas discursivas da articulista.

Em suma, o artigo de opinião é dialógico porque carrega em si ecos de outros discursos e enunciados circulantes na sociedade, como os discursos da redução da maioridade penal, da impunidade e do aumento dos casos de violência. Também é dialógico porque funciona como um elo de comunicação entre o eu e o outro, isto é, entre a autora e o sujeito leitor, instaurados discursivamente. Portanto, sob esses aspectos, o artigo analisado é dialógico. Tanto o sujeito que fala ou escreve, quanto o sujeito que o ouve ou lê, participam do ato comunicativo sem qualquer passividade. Isso está calcado no poder de ação conferido pela linguagem.

No entanto, o artigo não é polifônico, pois não cede lugar a outras vozes que poderiam contra-argumentar o ponto nodal defendido pela autora: a banalização da vida e da violência e as medidas que ela acredita serem necessárias para combater isso. Como estratégia discursiva, a polifonia requer que sejam empregadas diferentes vozes ou vozes plurais no enunciado ou no discurso. $\mathrm{O}$ artigo de opinião empreende um movimento contrário ao polifônico: silencia ou repudia as vozes que destoam da sua posição axiológica defendida.

Há, de um lado, "um sujeito que procura convencer o outro de alguma coisa, levá-lo a acreditar em algo, a sentir de certa forma e a fazer o que se quer que ele faça; de outro, um sujeito que interpreta o que lhe é proposto", podendo aderir ou não ao discurso proposto (BARROS, 2002, p. 17-18). Por ter ciência disso, isto é, da possibilidade da não adesão ao seu discurso, a articulista emprega o tom autoritário e monofônico ao seu enunciado, com a finalidade de enfraquecer o contraditório e fortalecer seu projeto discursivo.

\section{Considerações finais}

A comunicação realizada pelo artigo de opinião, enquanto ato comunicativo, e, portanto, um ato responsável, tem uma realidade histórica, social, econômica, cultural, simbólica, expressiva e material. Assim, o artigo constitui não só um artefato textual e cultural, mas um objeto éticoestético que serve ao estudo sociológico da linguagem.

Embora o artigo de opinião busque um diálogo, pois vai ao encontro de seus leitores, os quais são projetados na materialidade linguística do texto; os enunciados não jogam com as diversas vozes sociais citadas, senão com a posição axiológica contida na voz da autora. A voz plena, que enforma (molda) e controla o tom do texto refere-se ao posicionamento da articulista a respeito do tema tratado. Há, no artigo de opinião, os princípios dialógicos inerentes a todo ato de linguagem, no entanto, percebese a ausência de polifonia e o esforço discursivo de silenciamento das possíveis vozes dissidentes.

\section{Referências}

BAKHTIN, Mikhail. (1926) Le discours dans la vie et dans la poésie. In: TODOROV, Tzvetan. Mikhaïl Bakhtine: le principe dialogique. Paris: Éditions du Seuil, 1981.

BAKHTIN, Mikhail. (1930). La structure de l'énoncé. In: TODOROV, T. Mikhaïl Bakhtine: le principe dialogique. Paris: Éditions du Seuil, 1981.

BAKHTIN, Mikhail. (1963). Problemas da poética de Dostoievski. 3. ed. Rio de Janeiro: Forense-Universitária, 2005.

BAKHTIN, Mikhail. (1927. O freudismo. São Paulo: Perspectiva, 2001

BAKHTIN, Mikhail. (VOLOCHÍNOV) (1929). Marxismo e filosofia da linguagem. 3. ed. São Paulo: Hucitec, 1986.

BAKHTIN, Mikhail. (1961). Toward a reworking of the Dostoievsky book. In: Problems of Dostoievsky's poetics. (1963) 3. ed. Minneapolis: University of Minnesota Press, 1987.

BAKHTIN, Mikhail. (1963). Problems of Dostoievsky's poetics. 3. ed. Minneapolis: University of Minnesota Press, 1987.

BAKHTIN, Mikhail. (1975). Questões de literatura e estética: a teoria do romance. São Paulo: Hucitec, 1988.

BAKHTIN, Mikhail. (1979). Estética da criação verbal. 5. ed. São Paulo: Martins Fontes, 2010.

BARROS, Diana Luz P. de; BARROS, D. L. P. de. A comunicação humana. In: FIORIN, J. L. (Org.). Introdução à Linguística. São Paulo: Contexto, 2002. v. 1, p. 25-53.

MORSON, Gary Saul; EMERSON, Caryl. Mikhail Bakhtin: criação de uma prosaística. São Paulo: EDUSP, 2008.

TEZZA, Cristovão. Entre a prosa e a poesia: Bakhtin e o formalismo russo. Rio de Janeiro: Rocco, 2003.

TODOROV, Tzvetan. Mikhaïl Bakhtine: le principe dialogique. Paris: Éditions du Seuil, 1981.

Recebido: 25 de agosto de 2015.

Aprovado: 20 de novembro de 2015.

Contato: grazifk@yahoo.com.br

pires.veralu@gmail.com eder108@yahoo.com.br 